\title{
Electronic structure and optical properties of $\mathrm{ZnSiO}_{3}$ and $\mathrm{Zn}_{2} \mathrm{SiO}_{4}$
}

S. Zh. Karazhanov, P. Ravindran, H. Fjellvåg, and B. G. Svensson

Citation: Journal of Applied Physics 106, 123701 (2009); doi: 10.1063/1.3268445

View online: http://dx.doi.org/10.1063/1.3268445

View Table of Contents: http://aip.scitation.org/toc/jap/106/12

Published by the American Institute of Physics

\section{Articles you may be interested in}

Formation mechanism of $\mathrm{ZnSiO} O_{3}$ nanoparticles embedded in an amorphous interfacial layer between a $\mathrm{ZnO}$ thin film and an $n-\mathrm{Si}(001)$ substrate due to thermal treatment

Journal of Applied Physics 103, 083520 (2008); 10.1063/1.2902477

Preparation and characterization of $\mathrm{ZnO}$ particles embedded in $\mathrm{Si}_{2}$ matrix by reactive magnetron sputtering Journal of Applied Physics 97, 103509 (2005); 10.1063/1.1897493

Luminescence thermometry with $\mathrm{Zn}_{2} \mathrm{SiO}_{4}: \mathrm{Mn}^{2+}$ powder

Applied Physics Letters 103, 141912 (2013); 10.1063/1.4824208

Transformation mechanisms from metallic $\mathrm{Zn}$ nanocrystals to insulating $\mathrm{ZnSiO}_{3}$ nanocrystals in a $\mathrm{SiO}_{2}$ matrix due to thermal treatment

Applied Physics Letters 93, 221910 (2008); 10.1063/1.3040320

Mechanisms behind green photoluminescence in $\mathrm{ZnO}$ phosphor powders

Journal of Applied Physics 79, 7983 (1998); 10.1063/1.362349

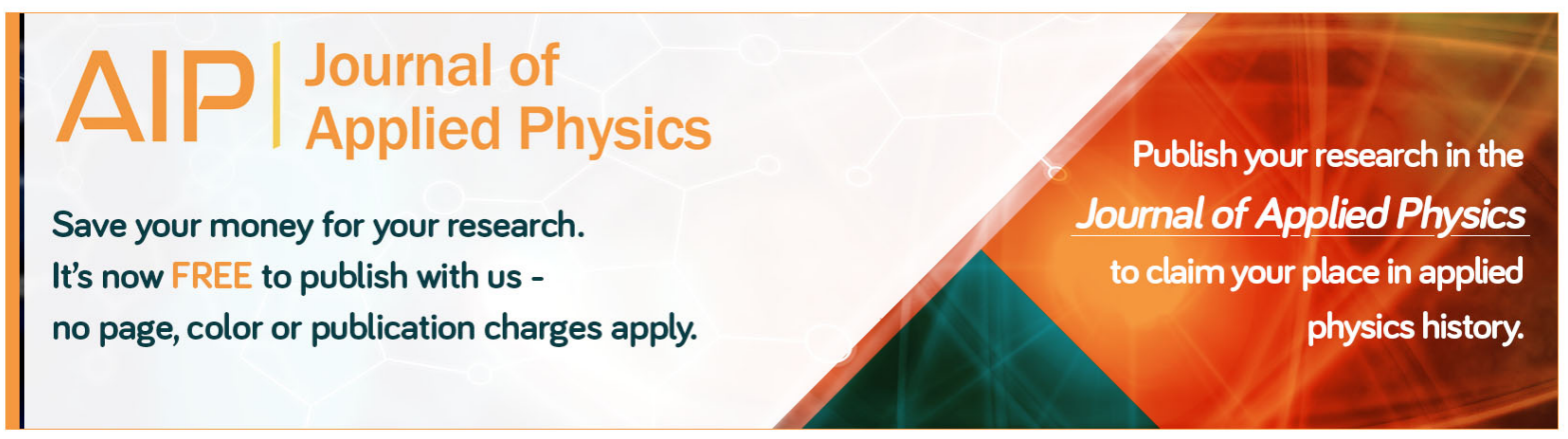




\title{
Electronic structure and optical properties of $\mathrm{ZnSiO}_{3}$ and $\mathrm{Zn}_{2} \mathrm{SiO}_{4}$
}

\author{
S. Zh. Karazhanov, ${ }^{1,2, a)}$ P. Ravindran, ${ }^{1}$ H. Fjellvåg, ${ }^{1}$ and B. G. Svensson ${ }^{3}$ \\ ${ }^{1}$ Department of Chemistry, Centre for Material Science and Nanotechnology, University of Oslo, \\ P.O. Box 1033 Blinden, N-0315 Oslo, Norway \\ ${ }^{2}$ Institute for Energy Technology, P.O. Box 40, NO-2027 Kjeller, Norway \\ ${ }^{3}$ Department of Physics, University of Oslo, P.O. Box 1048 Blindern, N-0316 Oslo, Norway
}

(Received 8 September 2009; accepted 29 October 2009; published online 16 December 2009)

\begin{abstract}
The electronic structure and optical properties of orthorhombic, monoclinic, and rhombohedral (corundum type) modifications of $\mathrm{ZnSiO}_{3}$, and of rhombohedral, tetragonal, and cubic (spinel type) modifications of $\mathrm{Zn}_{2} \mathrm{SiO}_{4}$ have been studied using $a b$ initio density functional theory calculations. The calculated fundamental band gaps for the different polymorphs and compounds are in the range $2.22-4.18 \mathrm{eV}$. The lowest conduction band is well dispersive similar to that found for transparent conducting oxides such as $\mathrm{ZnO}$. This band is mainly contributed by $\mathrm{Zn} 4 s$ electrons. The carrier effective masses were calculated and compared with those for $\mathrm{ZnO}$. The topmost valence band is much less dispersive and contributed by $\mathrm{O} 2 p$ and $\mathrm{Zn} 3 d$ electrons. From the analysis of charge density, charges residing in each site, and electron localization function, it is found that ionic bonding is mainly ruling in these compounds. The calculated optical dielectric tensors show that the optical properties of $\mathrm{ZnSiO}_{3}$ and $\mathrm{Zn}_{2} \mathrm{SiO}_{4}$ are almost isotropic in the visible part of the solar spectra and depend negligibly on the crystal structure. Within the $0-4 \mathrm{eV}$ photon energy range, the calculated magnitude of the absorption coefficient, reflectivity, refractive index, and extinction coefficient are smaller than $10^{3} \mathrm{~cm}^{-1}, 0.15,2.2$, and 0.3 , respectively, for all the $\mathrm{ZnSiO}_{3}$ and $\mathrm{Zn}_{2} \mathrm{SiO}_{4}$ phases considered in this work. This suggests that zinc silicates can be used as antireflection coatings. (C) 2009 American Institute of Physics. [doi:10.1063/1.3268445]
\end{abstract}

\section{INTRODUCTION}

$\mathrm{ZnSiO}_{3}$ shows useful properties such as excellent adhesion to steel surfaces, high heat resistance, high hardness, abrasion resistance, inertness to crude and refined oils, greases, and solvents, resistance to radiation (including nuclear radiation), and weather resistance. These silicates are predominantly used for buildings, offshore constructions, and bridges. They can be used as abrasion-resistant coating with controlled electrical conductivity. $\mathrm{ZnSiO}_{3}$ is very inert and, with exception of exposure to strong acids and alkalides, do not degrade in most industrial and marine environments. ${ }^{1}$ Nanodispersed $\mathrm{ZnSiO}_{3}$ codeposited on nickel-phosphorus alloys are corrosion ${ }^{2}$ as well as hightemperature oxidation resistant. Recently, a new crystalline phase of $\mathrm{ZnSiO}_{3}$ is reported, ${ }^{3}$ formed upon irradiation of nanocomposite $\mathrm{ZnO}-\mathrm{SiO}_{2}$ films with ultraviolet light. This crystalline phase is formed within the amorphous media by a photoinduced reaction. The monoclinic $\mathrm{ZnSiO}_{3}$ nanocrystals have been formed as a result of rapid thermal annealing of $\mathrm{SiO}_{2}$ with metallic $\mathrm{Zn}$ nanocrystals. ${ }^{4}$ Also by the transmission electron microscopy (TEM) $\mathrm{ZnSiO}_{3}$ nanoparticles have been found in between the $\mathrm{ZnO}$ thin film and the $\mathrm{Si}$ substrate. ${ }^{5}$ Moreover, from x-ray diffraction (XRD), TEM, and selected-area electron diffraction studies, orthorhombic $\mathrm{ZnSiO}_{3}$ is found at the interface of the $\mathrm{ZnO} / \mathrm{Si}$ heterostructure after annealing at $900{ }^{\circ} \mathrm{C}$ resulting from the interdiffusion between $\mathrm{ZnO}$ and $\mathrm{Si}^{6}$

\footnotetext{
${ }^{a}$ Author to whom correspondence should be addressed. Electronic mail: smagul.karazhanov@ife.no.
}

$\mathrm{Zn}_{2} \mathrm{SiO}_{4}$ is known under the mineralogical name willemite and belongs to the family of orthosilicates. ${ }^{3}$ It has numerous technological applications such as phosphor host, crystalline phase in glass ceramics, electrical insulators, glazes, and pigments (see, e.g., Ref. 7). Because of its unique luminescent properties, wide energy band gap $(5.5 \mathrm{eV})$, and excellent chemical stability, $\mathrm{Zn}_{2} \mathrm{SiO}_{4}$ is candidate for flat panel displays, ${ }^{8-13} \mathrm{X}$-ray or nuclear medical image receptors, $\mathrm{X}$ ray to light converters coupled to optical detectors, ${ }^{14}$ etc. $\mathrm{Zn}_{2} \mathrm{SiO}_{4}$ forms readily at the interface of $\mathrm{ZnO} / \mathrm{Si}$ heterostructures. ${ }^{15-17}$ Such $\mathrm{ZnO}$ deposited on silicate glass is used as a transparent conducting oxide (TCO) buffer in photovoltaic solar cells. ${ }^{18} \mathrm{Zn}_{2} \mathrm{SiO}_{4}$ has a large band offset (Fig. $1),{ }^{17}$ which can be one of the reasons for low $8.5 \%$ efficiency of crystalline $\mathrm{Si}-\mathrm{ZnO}$ solar cells. ${ }^{18}$ Using secondary ion mass spectroscopy, a vast interdiffusion was confirmed at the interface between $\mathrm{ZnO}$ film and $\mathrm{Si}$ substrate. ${ }^{15}$ By means of cathodoluminescence and glancing-angle XRD, the tetrago-

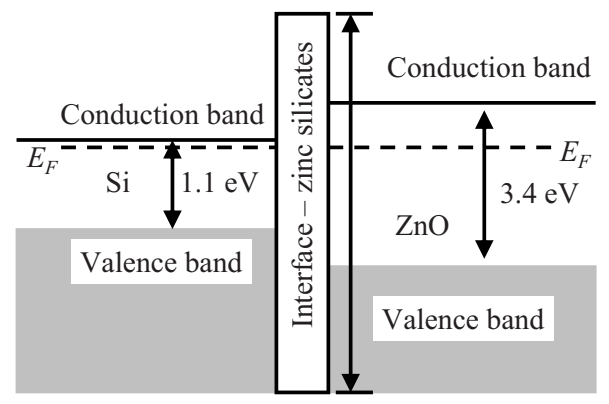

FIG. 1. Band diagram for the $\mathrm{Si}-\mathrm{ZnO}$ heterojunction with interface layer of zinc silicates located in between $\mathrm{Si}$ and $\mathrm{ZnO}$. 
nal modification of $\mathrm{Zn}_{2} \mathrm{SiO}_{4}$ was proved to be present. Moreover, XRD measurements have shown the existence of an earlier unknown rhombohedral modification of $\mathrm{Zn}_{2} \mathrm{SiO}_{4}$ at the boundary between $\mathrm{ZnO}$ particles and $\mathrm{SiO}_{2}$ matrix. ${ }^{19}$

Some information on electronic structure studies of $\mathrm{ZnSiO}_{3}, \mathrm{Zn}_{2} \mathrm{SiO}_{4}$, and similar compounds are already available. For example, $\mathrm{Zn}_{2} \mathrm{SiO}_{4}$ has been studied by the selfconsistent-field multiple-scattering $X \alpha$ cluster method, ${ }^{8,20}$ and hexagonal and tetragonal phases of $\mathrm{Zn}_{2} \mathrm{SiO}_{4}$ (Ref. 21) by the Vienna $a b$ initio simulation package (VASP). ${ }^{22}$ Fayalites $M_{2} \mathrm{SiO}_{4}(M=\mathrm{Fe}$ and $\mathrm{Co})$ have been investigated ${ }^{23}$ by the generalized-gradient approximation with the multiorbital mean-field Hubbard potential $(U)$. The related compounds $\mathrm{Zn}_{2} \mathrm{SnO}_{4}, \mathrm{Cd}_{2} \mathrm{SnO}_{4}$, and $\mathrm{In}_{2} \mathrm{CdO}_{4}$ have been examined ${ }^{24}$ by VASP. Possibility of phase transitions between structural polymorphs of $\mathrm{ZnSiO}_{3}$ and $\mathrm{Zn}_{2} \mathrm{SiO}_{4}$ have been reported ${ }^{25}$ by density functional theory (DFT) calculations using the VASP package. However, to our knowledge, there is no systematic study on the electronic structure and optical properties of the different polymorphs of $\mathrm{ZnSiO}_{3}$ and $\mathrm{Zn}_{2} \mathrm{SiO}_{4}$.

Knowledge on the electronic structure and optical property for zinc silicates are of interest for semiconductor electronics. Since the electronic structure of zinc silicates are quite different from those of $\mathrm{ZnO}, \mathrm{Si}$, and $\mathrm{SiO}_{2}$, any formation of zinc silicates at the interfaces can strongly influence optical and electrical properties of $\mathrm{ZnO}-\mathrm{Si}$ and $\mathrm{ZnO}-\mathrm{SiO}_{2}$ based optoelectronic devices. The above mentioned experimental results about existence of different polymorphs of the zinc silicates, possibility of their formation at the interface between $\mathrm{ZnO}-\mathrm{Si}$ and $\mathrm{ZnO}-\mathrm{SiO}_{2}$, create the necessity to study dependence of the electronic structure, electrical, and optical properties of the silicates on crystal structure and crystallographic directions. The other interesting point is dopability of the silicates by shallow level impurities and $\mathrm{H}$, which would allow one to classify the silicates as semiconductors or insulators. Another interesting point to be explored is the suggestion regarding usage of $\mathrm{Zn}_{2} \mathrm{SiO}_{4}$ and $\mathrm{ZnSiO}_{3}$ as passivation layers and studies of band alignment between the zinc silicates with other semiconductors. We hope that these points will motivate studies on these materials in the future. The aim of the present work is to study the electronic structure and optical properties of various polymorphs such as monoclinic $(m)$, orthorhombic $(o)$, and rhombohedral $(r) \mathrm{ZnSiO}_{3}$ as well as tetragonal $(t)$, cubic $(c)$, and $r-\mathrm{Zn}_{2} \mathrm{SiO}_{4}$.

\section{COMPUTATIONAL DETAILS}

Information on the crystal structures of the different crystallographic modifications of $\mathrm{ZnSiO}_{3}$ and $\mathrm{Zn}_{2} \mathrm{SiO}_{4}$ and corresponding positional and lattice parameters used in the present calculations are reported elsewhere (Ref. 25). For the studies of electronic structures and optical spectra, the VASP package $^{22}$ was used. The exchange and correlation energies were described by the Perdew-Zunger parametrization ${ }^{26}$ of the quantum Monte Carlo results of Ceperley-Alder. ${ }^{27}$ The interaction between electrons and atomic cores was described by means of non-norm-conserving pseudopotentials generated in accordance with the projector-augmented wave method. ${ }^{28,29}$ Orthonormalized all-electron-like wave functions have been constructed for the $\mathrm{Zn} 3 d$ and $\mathrm{Zn} 4 s$, Si $3 s$ and $\mathrm{Si} 3 p$, as well as $\mathrm{O} 2 s$ and $\mathrm{O} 2 p$ valence electrons. Spin-orbit coupling has not been included in the present calculations.

The diagonal elements of the effective mass tensor for the conduction band (CB) electrons are calculated by

$$
\frac{1}{m_{c}(k)}=\left.\frac{1}{\hbar^{2}} \frac{\partial^{2} E(k)}{\partial^{2} k}\right|_{k=k_{0}}
$$

in different directions in $k$ space from the $\Gamma$ point toward the other high-symmetry points in the Brillouin zone. We use this to give an indication for the carrier mobility, since the CB minimum of the band dispersions of all the compounds considered are located at the $\Gamma$ point of the Brillouin zone. The band edge energies $E(k)$ have been extracted from DFT calculations and ninth order polynomial fitting has been performed. From the fitted polynomial, the second order derivative was calculated, which was used in the effective mass calculations in Eq. (1).

The imaginary part of the optical dielectric function $\varepsilon_{2}(\omega)$ has been derived from DFT results by summing all allowed direct transitions from occupied to unoccupied states. From that the real part of the dielectric function $\varepsilon_{1}(\omega)$ is calculated using the Kramer-Kronig transformation. The knowledge of both the real and imaginary parts of the dielectric tensor allows one to calculate other important linear optical properties. In this paper, we present and analyze the reflectivity $R(\omega)$, the absorption coefficient $\alpha(\omega)$, the refractive index $n(\omega)$, and the extinction coefficient $k(\omega)$. More details about the optical calculations are discussed in Refs. 30 and 31 .

\section{RESULTS AND DISCUSSION}

\section{A. Band structure}

The electronic band structures are studied for the optimized crystal structures of various polymorphs of $\mathrm{ZnSiO}_{3}$ and $\mathrm{Zn}_{2} \mathrm{SiO}_{4}$ (Fig. 2). The corresponding band gaps $\left(E_{g}\right)$ were determined for both of the compounds (Table I). In the present computations, no band gap correction schemes have been applied. Hence the calculated fundamental band gaps are underestimated because of the well-known deficiency of DFT. The experimental $E_{g}$ value for $\mathrm{Zn}_{2} \mathrm{SiO}_{4}-r$ is in the range from 5.50 to $6.26 \mathrm{eV}$. The band gap of $4.36 \mathrm{eV}$ estimated from the band diagram for $\mathrm{Si}-\mathrm{ZnO}$ heterojunction based on the x-ray photoelectron spectroscopy studies ${ }^{17}$ corresponds probably to $\mathrm{Zn}_{2} \mathrm{SiO}_{4}-t$. The experimental band gap value for $\mathrm{ZnSiO}_{3}$ and other polymorphs of $\mathrm{Zn}_{2} \mathrm{SiO}_{4}$ are not yet available. The band gaps calculated by DFT within local density approximation are likely to be about $\sim 30 \%-50 \%$ smaller than actual experimental values. The real band gaps for these zinc silicates are expected to be $\sim 5.0 \mathrm{eV}$. These are hence classified as wide band gap solids.

In order to understand whether the considered compounds remain transparent in the visible spectra even after heavy doping by shallow donors, the difference in the energies between the $\mathrm{CB}$ minimum and the second nearest $\mathrm{CB} E_{g}^{s}$ has been calculated (Table I), also known as the second band 

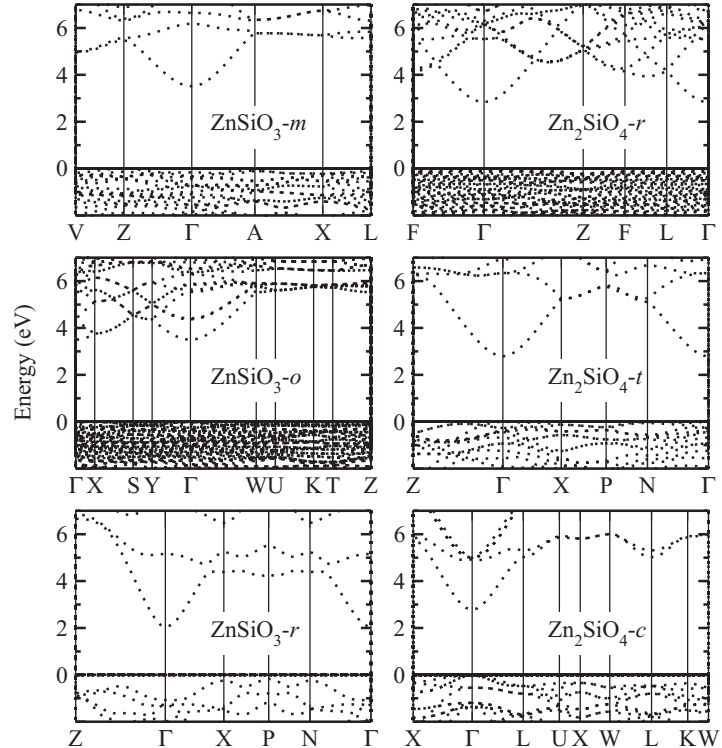

FIG. 2. Band structure for polymorphs of $\mathrm{ZnSiO}_{3}$ and $\mathrm{Zn}_{2} \mathrm{SiO}_{4}$ in the high symmetry directions of the Brillouin zone. The Fermi level is set to zero.

gap. ${ }^{24}$ The analysis shows that the value of $E_{g}^{s}$ for $\mathrm{ZnSiO}_{3}-r$ is $\sim 2.8 \mathrm{eV}$. Consequently, if $\mathrm{ZnSiO}_{3}-r$ can possess $n$-type metalliclike electrical conductivity, it can be considered as TCO. For the other $\mathrm{ZnSiO}_{3}$ and $\mathrm{Zn}_{2} \mathrm{SiO}_{4}$ polymorphs, the calculated $E_{g}^{s}$ values are smaller than $2.5 \mathrm{eV}$. The value of $E_{g}^{s}$ depends on the crystal structure and the particular chemical composition.

The bands around the valence band (VB) maximum are very close to each other for the various $\mathrm{ZnSiO}_{3}$ and $\mathrm{Zn}_{2} \mathrm{SiO}_{4}$ polymorphs and consequently, it is hard for the eye to analyze the dispersion as well as the character of the topmost VB. In Fig. 2 the band structures are therefore plotted in the vicinity of the fundamental band gap. This allows us to classify these semiconductors as either direct or indirect band gap materials. In Fig. 2 the dispersion of the band around the VB maximum is clearly seen for $\mathrm{ZnSiO}_{3}-r, \mathrm{Zn}_{2} \mathrm{SiO}_{4}-t$, and $\mathrm{Zn}_{2} \mathrm{SiO}_{4}-c$. For the other $\mathrm{ZnSiO}_{3}$ and $\mathrm{Zn}_{2} \mathrm{SiO}_{4}$ polymorphs, the plotting of $\mathrm{VB}$ is done for a very small energy range, i.e., -0.4 to $0.0 \mathrm{eV}$. For all the considered polymorphs of $\mathrm{ZnSiO}_{3}$

TABLE I. Calculated fundamental band gap $E_{g}$, second gap $E_{g}^{s}$, and experimental gap $E_{g}^{\exp }$ (in eV) for polymorphs of $\mathrm{ZnSiO}_{3}$ and $\mathrm{Zn}_{2} \mathrm{SiO}_{4}$.

\begin{tabular}{lcccc}
\hline \hline Compound & $E_{g}$ & & $E_{g}^{s}$ & $E_{g}^{\exp }$ \\
\hline $\mathrm{ZnSiO}_{3}-o$ & 3.50 & Direct & 0.86 & \\
$\mathrm{ZnSiO}_{3}-m$ & 3.68 & Indirect & 1.45 & \\
$\mathrm{ZnSiO}_{3}-r$ & 4.18 & Indirect & 2.80 & \\
$\mathrm{Zn}_{2} \mathrm{SiO}_{4}-t$ & 2.22 & Direct & 2.45 & \\
$\mathrm{Zn}_{2} \mathrm{SiO}_{4}-r$ & 2.83 & Direct & 1.44 & $5.50,{ }^{\mathrm{a}} 5.30,{ }^{\mathrm{b}} 6.15,{ }^{\mathrm{c}} 6.26,{ }^{\mathrm{d}}$ \\
$\mathrm{Zn}_{2} \mathrm{SiO}_{4}-c$ & 2.78 & Direct & 2.11 & $4.36^{\mathrm{e}}$ \\
\hline
\end{tabular}

${ }^{a}$ Sol-gel derived zinc silicate phosphor films used for full-color display applications (Ref. 10).

${ }^{b} \mathrm{ZnO}$ nanoparticles formed in $\mathrm{SiO}_{2}$ by ion implantation combined with thermal oxidation (Ref. 43).

${ }^{\mathrm{c}} \mathrm{ZnO}$ particles embedded into $\mathrm{SiO}_{2}$ by reactive magnetron sputtering (Ref. 19).

${ }^{\mathrm{d}} \mathrm{ZnO}$ particles embedded into $\mathrm{SiO}_{2}$ by reactive magnetron sputtering (Ref. 19).

${ }^{\mathrm{e}} \mathrm{Zn}_{2} \mathrm{SiO}_{4}$ formed at the $\mathrm{Si}-\mathrm{ZnO}$ interface (Ref. 17).

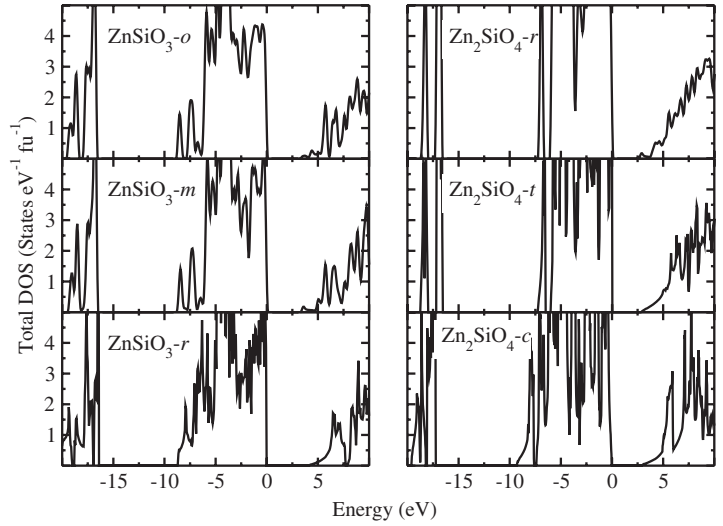

FIG. 3. Total DOS for $\mathrm{ZnSiO}_{3}$ and $\mathrm{Zn}_{2} \mathrm{SiO}_{4}$ polymorphs. The Fermi level is set to zero.

and $\mathrm{Zn}_{2} \mathrm{SiO}_{4}$, the $\mathrm{CB}$ minimum is located at the $\Gamma$ point (see Fig. 2). The $\mathrm{VB}$ maximum for $\mathrm{ZnSiO}_{3}-o$, and $\mathrm{Zn}_{2} \mathrm{SiO}_{4}-r$, $\mathrm{Zn}_{2} \mathrm{SiO}_{4^{-}}$, and $\mathrm{Zn}_{2} \mathrm{SiO}_{4^{-}} c$ are located at the $\Gamma$ point and hence they can be classified as direct band gap semiconductors, see Table I. However, the VB maxima for both $\mathrm{ZnSiO}_{3}-m$ and $\mathrm{Zn}_{2} \mathrm{SiO}_{4}-r$ are located aside the $\Gamma$ point. So, these two polymorphs have an indirect band gap.

The ability to easily conduct electricity is one of the key feature of TCOs. Qualitative information about this feature can be derived from the analysis of the band dispersion at the band extremes. Analysis of Fig. 2 shows that the bottommost CB for all polymorphs of $\mathrm{ZnSiO}_{3}$ and $\mathrm{Zn}_{2} \mathrm{SiO}_{4}$ are well dispersive. Consequently, one can expect that the electrical conductivity by $\mathrm{CB}$ electrons is favorable in these materials and this can be achieved by electron doping. Compared with the bottommost $\mathrm{CB}$, the topmost $\mathrm{VB}$ for $\mathrm{ZnSiO}_{3}$ and $\mathrm{Zn}_{2} \mathrm{SiO}_{4}$ phases are almost dispersionless in the whole Brillouin zone. So, electrical conductivity by holes cannot be as good as that by $\mathrm{CB}$ electrons. This behavior also indicates that the outermost valence electrons are tightly bonded to their host atoms. As discussed in Sec. III B, strong contribution to the topmost $\mathrm{VB}$ is coming from $\mathrm{O}$ and $\mathrm{Zn}$ atoms whereas that from $\mathrm{Si}$ is negligible. Consequently, one can suggest that the outermost $\mathrm{VB}$ electrons are tightly bonded to $\mathrm{O}$ and the $\mathrm{Zn}-\mathrm{O}$ bond has a distinct ionic component. The dispersive nature of the topmost $\mathrm{VB}$ is largest for the $\mathrm{ZnSiO}_{3}-r, \mathrm{Zn}_{2} \mathrm{SiO}_{4}-t$, and $\mathrm{Zn}_{2} \mathrm{SiO}_{4}-c$ polymorphs. This indicates that different hybridization schemes play an important role for the carrier mobility.

\section{B. Density of states}

The band structure in the vicinity of CB and VB edges are analyzed above. Knowledge on the distribution of all valence electrons is obtained from the density of states (DOS). Such analyses are performed for the zinc silicate polymorphs in Fig. 3. It is seen that the VB consists of two major regions. The lower VB1 region in the energy range from -20 to $-17 \mathrm{eV}$ is relatively narrow and splits into sharp subbands. The VB2 region above VB1 covers the range from -9.5 to VB maximum and has broad features. In order to gain more insight into the VBs and CBs as well as into the chemical bonding, the orbital and site projected DOS 


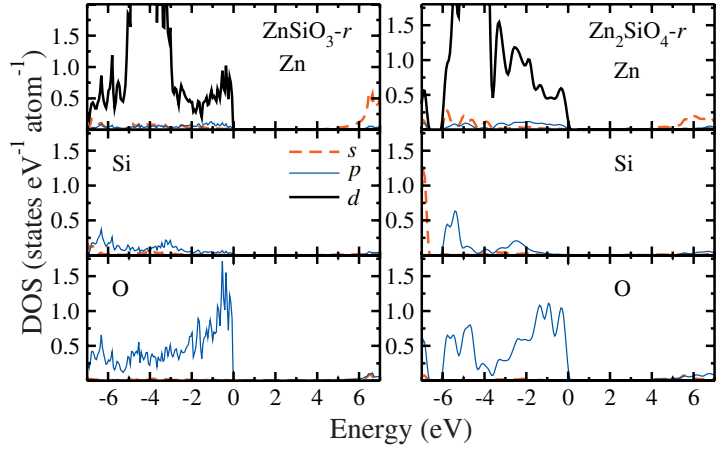

FIG. 4. (Color) The orbital and site-projected DOS for monoclinic $\mathrm{ZnSiO}_{3}-m$, and $\mathrm{Zn}_{2} \mathrm{SiO}_{4}-r$. The Fermi level is set to zero.

(PDOS) were analyzed. Figure 4 shows the PDOS for $\mathrm{ZnSiO}_{3}-m$ and $\mathrm{Zn}_{2} \mathrm{SiO}_{4}-r$. It is seen that VB1 consists mainly of $\mathrm{O} 2 s$ with smaller contributions from hybridized $\mathrm{Si} 3 s$ and $3 p$ electrons. The VB2 consists of three parts: The lowest energy region is basically contributed from $\mathrm{Si} 3 s$ electrons. The intermediate energy region consists of very sharp peaks located around $-5 \mathrm{eV}$ that originates from $\mathrm{Zn} 3 d$ electrons. The topmost part is hybridized $\mathrm{Zn} 3 d$ and the O $2 p$ states, while contributions from $\mathrm{Si} 3 p$ states are negligible. This indicates that the topmost VB can drastically be modified by controlling the $\mathrm{Zn}$ and/or O stoichiometry.

The CB edge is well dispersed and consists basically of $\mathrm{Zn} 4 s$ electrons, with smaller contribution from both $\mathrm{O} 2 \mathrm{~s}$ and $\mathrm{Si} 3 s$. Hence, the $\mathrm{Zn} 4 s$ electrons at the CB minimum play an important role in the electrical conductivity for all these zinc silicate polymorphs. Since the contribution from the $\mathrm{Si} 3 s$ and $\mathrm{O} 2 s$ electrons to the $\mathrm{CB}$ edge is smaller than that from the $\mathrm{Zn} 4 s$ electrons, one can say that they play almost no role in the effective mass of the CB electrons.

The large band gap means that the band offset between the zinc silicate and $\mathrm{Si}$ or $\mathrm{ZnO}$ will be large. The offset between CBs and VBs of $n-\mathrm{ZnO}$ and $p^{+}-\mathrm{Si}$ is $0.30 \mathrm{eV}$ (Ref. 32) and $2.55 \mathrm{eV}^{33}$ respectively. Since the band gap of $\mathrm{ZnSiO}_{3}$ and $\mathrm{Zn}_{2} \mathrm{SiO}_{4}$ polymorphs can be larger than that of $\mathrm{ZnO}$, one can expect that the offset between $\mathrm{CB}(\mathrm{VB}) \mathrm{s}$ of the silicates and $\mathrm{ZnO}(\mathrm{Si})$ will be different from the above mentioned values. This will certainly affect the performance of device structures.

\section{CB effective masses}

As noted above (see also Fig. 2), the states at the CB minimum are much more dispersive than the topmost $\mathrm{VB}$ states. Consequently, CB electrons are lighter than holes and

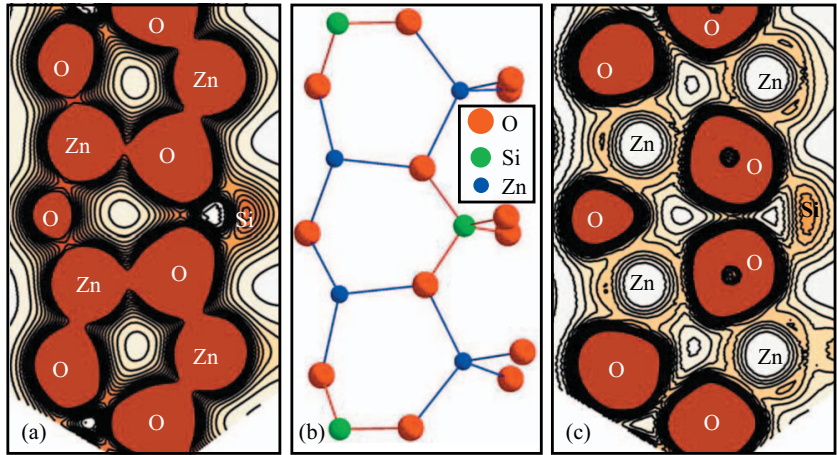

FIG. 5. (Color) (a) Charge density and (c) ELF for $\mathrm{Zn}_{2} \mathrm{SiO}_{4}-r$ corresponding to the atomic plane schematically presented in (b).

hence the influence of the latter on the electrical conductivity will be minimal. For quantitative characterization of carrier mobility, the calculated effective masses around the bottommost CB extremes are given in Table II. Analysis shows that the effective masses for electrons in $\mathrm{ZnSiO}_{3}$ and $\mathrm{Zn}_{2} \mathrm{SiO}_{4}$ polymorphs are almost isotropic. Hence, the $\mathrm{CB}$ electron mobility and electrical conductivity of the compounds are expected to be isotropic as well. At present there are no experimental data available.

The CB electron masses for $\mathrm{ZnSiO}_{3}-o, \mathrm{ZnSiO}_{3}-m$ and $\mathrm{Zn}_{2} \mathrm{SiO}_{4}-t$ are of the same magnitude, whereas those for $\mathrm{Zn}_{2} \mathrm{SiO}_{4}-r$ are about four times larger. Hence, the electrical conductivity for $\mathrm{Zn}_{2} \mathrm{SiO}_{4}-r$ is expected to be smaller than that for other modifications of $\mathrm{ZnSiO}_{3}$ and $\mathrm{Zn}_{2} \mathrm{SiO}_{4}$. The calculated CB electron effective mass of around $1.24 m_{0}$ for $\mathrm{Zn}_{2} \mathrm{SiO}_{4}-r$ is, however, much larger than that for well known TCOs, for example, $0.23 m_{0}$ (Ref. 34) and $0.24 m_{0}$ (Ref. 35) for $\mathrm{ZnO}, \sim 0.23 m_{0}$ for $\mathrm{Zn}_{2} \mathrm{SnO}_{4}, \sim 0.18 m_{0}$ for $\mathrm{Cd}_{2} \mathrm{SnO}_{4}$, and $\sim 0.17 m_{0}$ for $\mathrm{CdIn}_{2} \mathrm{O}_{4} \cdot{ }^{24}$ Consequently, the mobility of $\mathrm{CB}$ electrons as well the electrical conductivity in $\mathrm{Zn}_{2} \mathrm{SiO}_{4}-r$ is expected to be small.

\section{Chemical bonding and charge density analysis}

A more detailed understanding of the bonding behavior can be obtained from charge density and electron localization function (ELF) analysis. ${ }^{36-38}$ Figure 5(a) presents the charge density distribution for $\mathrm{Zn}-\mathrm{O}$ and $\mathrm{Si}-\mathrm{O}$ bonds of $\mathrm{Zn}_{2} \mathrm{SiO}_{4}-r$. The compounds $\mathrm{Zn}_{2} \mathrm{SiO}_{4}-t, \mathrm{ZnSiO}_{3}-o, \mathrm{ZnSiO}_{3}-m$, and $\mathrm{ZnSiO}_{3}-r$ exhibit similar features to that of $\mathrm{Zn}_{2} \mathrm{SiO}_{4}-r$. It is found that the largest charge density is residing at the $\mathrm{Zn}$ and $\mathrm{O}$ atoms. A large amount of localized electrons are present around $\mathrm{Zn}$. These are semicore $\mathrm{Zn} 3 d$ electrons considered as valence electrons in the computation. The charge around $\mathrm{Si}$

TABLE II. Effective masses of CB electrons (in units of free-electron mass $m_{0}$ ) for $\mathrm{ZnSiO}_{3}$ and $\mathrm{Zn}_{2} \mathrm{SiO}_{4}$ polymorphs along with those for $\mathrm{ZnO}$.

\begin{tabular}{ccccc}
\hline \hline $\mathrm{ZnSiO}_{3}-o$ & $\mathrm{ZnSiO}_{3}-m$ & $\mathrm{Zn}_{2} \mathrm{SiO}_{4}-r$ & $\mathrm{Zn}_{2} \mathrm{SiO}_{4^{-}} t$ & $\mathrm{ZnO}$ \\
\hline $0.372(\Gamma \rightarrow \mathrm{X})$ & $0.335(\Gamma \rightarrow \mathrm{A})$ & $1.226(\Gamma \rightarrow \mathrm{F})$ & $0.316(\Gamma \rightarrow \mathrm{N})$ & $0.14,{ }^{\mathrm{a}} 0.23,{ }^{\mathrm{b}} 0.24^{\mathrm{c}}(\Gamma \rightarrow \mathrm{A})$ \\
$0.353(\Gamma \rightarrow \mathrm{W})$ & $0.430(\Gamma \rightarrow \mathrm{Z})$ & $1.240(\Gamma \rightarrow \mathrm{L})$ & $0.378(\Gamma \rightarrow \mathrm{X})$ & $0.14,{ }^{\mathrm{a}} 0.21^{\mathrm{b}}(\Gamma \rightarrow \mathrm{M})$ \\
$0.390(\Gamma \rightarrow \mathrm{Y})$ & & $1.240(\Gamma \rightarrow \mathrm{Z})$ & $0.470(\Gamma \rightarrow \mathrm{Z})$ & \\
\hline
\end{tabular}

${ }^{\mathrm{a}}$ Calculated by VASP (Ref. 44).

${ }^{\mathrm{b}}$ Calculated from full-potential linear muffin-tin orbital method (Ref. 34).

${ }^{c}$ Experimental value from Ref. 35. 
is smaller than that around $\mathrm{Zn}$. On the one hand, this is because Si does not have $d$ electrons and, on the other hand, as demonstrated by the analysis of the Bader charge in the following section, Si donates to O more charge than $\mathrm{Zn}$. This result is consistent with the analysis of PDOS (Fig. 4), which shows that the population of the Si site by electrons is smaller than that of the $\mathrm{Zn}$. This result is reasonable also because the spectroscopic electronegativities of $\mathrm{Zn}$ and $\mathrm{Si}$ are 1.65 and $1.90,{ }^{39}$ respectively. Since the electronegativity of $\mathrm{O}$ is 3.44, the ionic interaction between $\mathrm{Zn}$ and $\mathrm{O}$ as well as between $\mathrm{Si}$ and $\mathrm{O}$ is more enhanced than covalent bonding.

According to PDOS (Fig. 4), the bonding mechanism in the zinc silicates is the hybridization between $\mathrm{Zn} 3 d$, Si $3 p$, and $\mathrm{O} 2 p$ states. The $\mathrm{Si}-\mathrm{O}$ bonds can be characterized as having both ionic and covalent characters: covalent because the $\mathrm{O} 2 p$ states are noticeably hybridized with $\mathrm{Si} 3 p$ states in large energy range in close vicinity of the $\mathrm{CB}$ and VB edges, ionic because the main peaks of $\mathrm{O} 2 p, \mathrm{Zn} 4 s$, and $\mathrm{Si} 3 p$ states are located in different energy ranges. Contribution of the $\mathrm{O} 2 p$ states is predominant in the energy range -1 to 0 $\mathrm{eV}$, whereas the $\mathrm{Zn} 4 s$ and $\mathrm{Si} 3 p$ states are dominant in the bands located in close vicinity of the CB edge.

The ELF is a useful tool to characterize the chemical bonding $^{40-42}$ as it measures the probability distribution of paired electrons. Figure 5(b) presents the calculated ELF plot. Analysis shows that the ELF value is small around $\mathrm{Zn}$ and $\mathrm{Si}$. The ELF distribution around $\mathrm{O}$ is larger and this shows that the electrons are transferred from $\mathrm{Zn}$ and $\mathrm{Si}$ to the $\mathrm{O}$ sites, i.e., strong ionic character. The ELF contours are not spherically shaped indicating the presence of noticeable directional bonding.

The smallest and largest distances between $\mathrm{Zn}$ and $\mathrm{O}$ atoms in the zinc silicates in Fig. 5 are 1.972 and $1.952 \AA$, respectively. Those between $\mathrm{Si}$ and $\mathrm{O}$ are equal to 1.637 and $1.611 \AA$. This result indicates that the strongest bonding in this solid is between $\mathrm{Si}$ and $\mathrm{O}$, which might possess covalent character as well. It follows from analysis of Fig. 4 that in the energy range -4 to $0 \mathrm{eV}$ where the $\mathrm{O} 2 p$ have the strong weight, there are also $\mathrm{Si} 3 s$ and $3 p$ as well as $\mathrm{Zn} 4 p$-like electrons, and $3 d$ and $4 s$ electrons. As discussed in previous studies ${ }^{30}$ this result indicates to the existence of covalence in the chemical bonding between $\mathrm{Si}$ and $\mathrm{O}$ as well as between $\mathrm{Zn}$ and $\mathrm{O}$. Furthermore, the nonspherical charges around the $\mathrm{Zn}, \mathrm{Si}$, and $\mathrm{O}$ atoms are the indications of the covalent character of the chemical bonding. covalence.

For quantitative analysis of charge transfer, several schemes are available for partitioning the space between atoms. In this work, we use Bader and Voronoi charge analysis. ${ }^{36-38}$ According to the Bader topological analysis, each atom is surrounded by a surface that run through minima of the charge density. These regions are known as Bader regions. This partitioning estimates the total charge around each atom by integrating the electron density within the Bader region. In the Voronoi charge analysis, each grid point of charge density is assigned to the nearest atom, but these distances are not scaled by the radius of the involved atom. The reported Voronoi charges are presently just used for checking of consistency.
TABLE III. Atomic effective charges (in units of electron charge $\mathrm{e}^{-}$) within the atomic basins of $\mathrm{Zn}, \mathrm{Si}$, and $\mathrm{O}$ calculated according to Bader's topological analysis (denoted by Bader) and Voronoi deformation density (denoted by Voronoi) in $\mathrm{ZnSiO}_{3}-m, \mathrm{Zn}_{2} \mathrm{SiO}_{4}-r, \mathrm{Zn}_{2} \mathrm{SiO}_{4}-t$, and $\mathrm{ZnO}$.

\begin{tabular}{lcrr}
\hline \hline Compound & Atom & Voronoi & Bader \\
\hline $\mathrm{ZnSiO}_{3}-m$ & $\mathrm{Zn}$ & 0.91 & 0.65 \\
& $\mathrm{Si}$ & 1.41 & 2.00 \\
& $\mathrm{O} 1$ & -0.69 & -0.81 \\
& $\mathrm{O} 2$ & -0.71 & -0.78 \\
& $\mathrm{O}$ & -0.78 & -1.06 \\
& $\mathrm{Zn} 1$ & 0.38 & \\
$\mathrm{Zn}_{2} \mathrm{SiO}_{4}-r$ & $\mathrm{Zn} 2$ & 0.88 & 0.65 \\
& $\mathrm{Si}$ & 1.52 & 0.68 \\
& $\mathrm{O} 1$ & -0.87 & 1.89 \\
& $\mathrm{O} 2$ & -0.88 & -0.85 \\
& $\mathrm{O} 3$ & -0.81 & -0.76 \\
& $\mathrm{O} 4$ & -0.49 & -0.74 \\
& & & \\
$\mathrm{Zn}{ }_{2} \mathrm{SiO}_{4}-t$ & $\mathrm{Zn} 1$ & 0.78 & 0.60 \\
& $\mathrm{Zn} 2$ & 0.85 & 0.61 \\
& $\mathrm{Si}$ & 1.45 & 1.96 \\
& $\mathrm{O} 1$ & -0.91 & -0.82 \\
$\mathrm{ZnO}$ & $\mathrm{O} 2$ & -0.46 & -0.72 \\
& $\mathrm{O} 3$ & -0.77 & -0.79 \\
& $\mathrm{O} 4$ & -0.90 & -0.84 \\
& $\mathrm{Zn}$ & 0.26 & 0.55 \\
& $\mathrm{O}$ & -0.70 & -0.55 \\
\hline
\end{tabular}

The results for some zinc silicates are presented in Table III. As expected, $\mathrm{Zn}$ and $\mathrm{Si}$ atoms donate electrons, while $\mathrm{O}$ atoms are acceptors. The amount of the donated charge indicates ionic type of chemical bonding between $\mathrm{Zn}$ and $\mathrm{O}$ as well as polar covalent bonding between $\mathrm{Si}$ and $\mathrm{O}$. Analysis shows that the amount of charge donated by $\mathrm{Zn}$ to $\mathrm{O}$ in the zinc silicates is larger than that in $\mathrm{ZnO}$.

\section{E. Optical properties}

Figure 6 presents the optical dielectric response function for $\mathrm{ZnSiO}_{3}$ and $\mathrm{Zn}_{2} \mathrm{SiO}_{4}$. In order to describe the optical anisotropy, three diagonal components of the dielectric func-

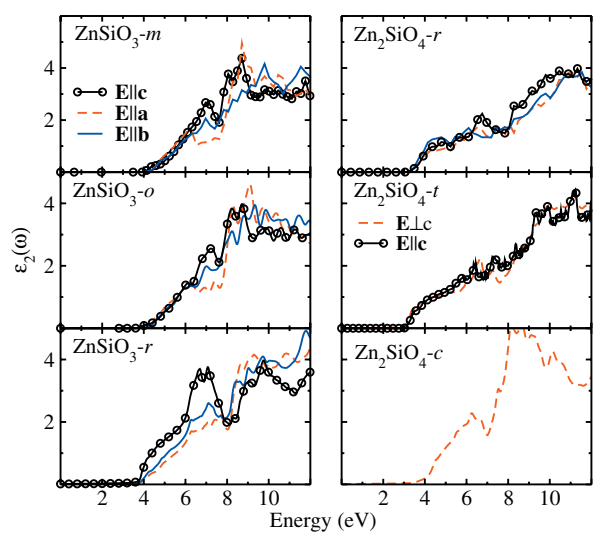

FIG. 6. (Color) Dielectric response functions for polymorphs of $\mathrm{ZnSiO}_{3}$ and $\mathrm{Zn}_{2} \mathrm{SiO}_{4}$ for the different directions of the electric field $\mathbf{E}$ compared to the $\mathbf{a}$, $\mathbf{b}$, and $\mathbf{c}$ axes. 


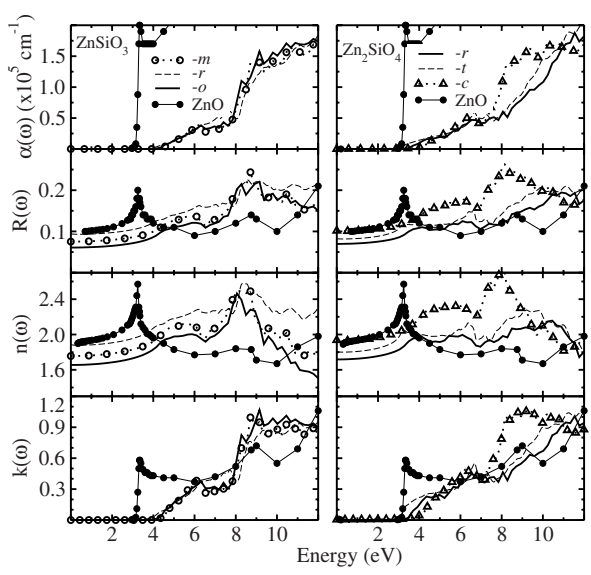

FIG. 7. (Color online) The calculated optical spectra for $\mathrm{ZnSiO}_{3}$ and $\mathrm{Zn}_{2} \mathrm{SiO}_{4}$ polymorphs as compared to those determined experimentally for $\mathrm{ZnO}$ (Ref. 45).

tion are calculated for $\mathrm{ZnSiO}_{3}-o$, six for $\mathrm{ZnSiO}_{3}-m$, and two for $\mathrm{Zn}_{2} \mathrm{SiO}_{4}-t$ and $\mathrm{Zn}_{2} \mathrm{SiO}_{4}-r$. Among the six components for $\mathrm{ZnSiO}_{3}-m$, the off-diagonal components are found to be negligible and hence the analysis is made just for the three diagonal components corresponding to the electric field $\mathbf{E}$ parallel to the crystallographic a, b, and c axes. Cubic $\mathrm{Zn}_{2} \mathrm{SiO}_{4}-c$ has isotropic optical properties.

Figure 6 presents the imaginary part of the optical dielectric function as a function of energy $\left[\varepsilon_{2}(\omega)\right]$ with electric field along different optical directions. The variation in $\varepsilon_{2}(\omega)$ for different crystallographic directions is very small. Consequently, the optical spectra are more or less isotropic. Figure 7 displays the absorption coefficient $\alpha(\omega)$, reflectivity $R(\omega)$, refractive index $n(\omega)$, and extinction coefficient $k(\omega)$ for polymorphs of $\mathrm{ZnSiO}_{3}$ and $\mathrm{Zn}_{2} \mathrm{SiO}_{4}$. The analyses of Figs. 6 and 7 show that the optical spectra are quite independent of crystallographic direction and lattice type. Consequently, amorphous $\mathrm{ZnSiO}_{3}$ and $\mathrm{Zn}_{2} \mathrm{SiO}_{4}$ might possess similar optical properties as their crystalline counterparts at energies larger than the fundamental band gap.

Analysis of Fig. 7 shows that in the energy range 0-4 $\mathrm{eV}$, the calculated absorption coefficient $\alpha(\omega)$, reflectivity $R(\omega)$, refractive index $n(\omega)$, and extinction coefficient $k(\omega)$ for zinc silicates are considerably smaller than those determined experimentally for $\mathrm{ZnO}$. It is well known that DFT underestimates the band gaps. Consequently, the calculated optical spectra will be shifted toward lower energies relative to the experimental spectra. To fix error, sometimes the optical spectra are rigidly shifted toward larger energies up to the experimentally determined location. Since no experimental data are available in the present work, the rigid shift technique has not been applied. Hence, one can expect that $\alpha(\omega)$, $R(\omega), n(\omega)$, and $k(\omega)$ of the $\mathrm{ZnSiO}_{3}$ and $\mathrm{Zn}_{2} \mathrm{SiO}_{4}$ polymorphs will be smaller than those of $\mathrm{ZnO}$ in wider energy range than $0-4 \mathrm{eV}$ (Fig. 7). Currently, the theoretical results indicate the possibility of using these silicates as antireflection coatings. Studies of defects, electrical current transport properties of the zinc silicates and their band alignment with other semiconductors will be the subject of future studies. We hope that our theoretical results will motivate experimental studies on these materials.

\section{CONCLUSIONS}

The presents $a b$ initio studies of electronic structure and optical properties of $\mathrm{ZnSiO}_{3}$ and $\mathrm{Zn}_{2} \mathrm{SiO}_{4}$ polymorphs show that these compounds are wide band gap solids with direct or indirect band gap depending on type polymorph. The bottommost $\mathrm{CB}$ is dispersive and is contributed mainly by $\mathrm{Zn} 4 s$ electrons. The topmost VB is almost dispersionless and is contributed by $\mathrm{O} 2 p$ and $\mathrm{Zn} 3 d$ electrons. From considerations of charge density, Bader and Voronoi charge calculations, and ELF, it is shown that these compounds possess significant ionic contributions to the bonding. The optical properties of all compounds are close to isotropic and for these the particular structural modification appears to have less importance. Based on the magnitude of the absorption coefficient $\left(<10^{3} \mathrm{~cm}^{-1}\right)$, reflectivity $(<0.15)$, refractive index $(<2.20)$, and extinction coefficient $(<0.30)$, all these $\mathrm{ZnSiO}_{3}$ and $\mathrm{Zn}_{2} \mathrm{SiO}_{4}$ polymorphs can be used as antireflection coatings in optoelectronic devices.

\section{ACKNOWLEDGMENTS}

This work has been funded by the Research Council of Norway through the NANOMAT program and from FOET Project No. 142327. Supercomputing support has been received from NOTUR facilities. S.Z.K thanks Dr. A. Klaveness and Dr. K. Knizek (Institute of Physics ASCR, Prague, Czech Republic) for discussions and help in computations.

${ }^{1}$ J. M. Keijman, PCE ' 99 Conference (The Brighton Centre, Brighton, England, 1999).

${ }^{2}$ P. Tao, M. Mei-Hua, X. Fei-Bo, and X. Xin-Quan, Appl. Surf. Sci. 181, 191 (2001)

${ }^{3}$ N. Taghavinia, H. Y. Lee, H. Makino, and T. Yao, Nanotechnology 16, 944 (2005).

${ }^{4}$ J. M. Yuk, J. Y. Lee, Y. S. No, T. W. Kim, and W. K. Choi, Appl. Phys. Lett. 93, 221910 (2008).

${ }^{5}$ J. W. Shin, Y. S. No, T. W. Kim, and W. K. Choi, J. Nanosci. Nanotechnol. 8, 5566 (2008).

${ }^{6}$ J. M. Yuk, J. Y. Lee, J. H. Jung, D. U. Lee, T. W. Kim, D. I. Son, and W. K. Choi, J. Appl. Phys. 103, 083520 (2008).

${ }^{7}$ G. T. Chandrappa, S. Ghosh, and K. C. Patil, J. Mater. Synth. Process. 7, 273 (1999).

${ }^{8}$ K. C. Mishra, K. H. Johnson, B. G. Deboer, J. K. Berkowitz, J. Olsen, and E. A. Dale, J. Lumin. 47, 197 (1991).

${ }^{9}$ M. Cich, K. Kim, H. Choi, and S. T. Hwang, Appl. Phys. Lett. 73, 2116 (1998).

${ }^{10}$ Q. Y. Zhang, K. Pita, and C. H. Kam, J. Phys. Chem. Solids 64, 333 (2003).

${ }^{11}$ B. W. Jeoung, G. Y. Hong, B. Y. Han, and J. S. Yoo, Jpn. J. Appl. Phys. 43, 7997 (2004)

${ }^{12}$ J. Wan, X. Chen, Z. Wang, L. Mu, and Y. Qian, J. Cryst. Growth 280, 239 (2005).

${ }^{13}$ F. H. Su, B. S. Ma, K. Ding, G. H. Li, S. P. Wang, W. Chen, A. G. Joly, and D. E. McCready, J. Lumin. 116, 117 (2006).

${ }^{14}$ I. Kandarakis, D. Cavouras, P. Prassopoulos, E. Kanellopoulos, C. D. Nomicos, and G. S. Panayiotakis, Appl. Phys. A: Mater. Sci. Process. 67, 521 (1998).

${ }^{15}$ X. Xu, P. Wang, Z. Qi, M. Hai, J. Xu, H. Liu, C. Shi, G. Lu, and W. Ge, J. Phys.: Condens. Matter 15, L607 (2003).

${ }^{16}$ X. L. Xu, C. X. Guo, Z. M. Qi, H. T. Liu, J. Xu, C. S. Shi, C. Chong, W. H. Huang, Y. J. Zhou, and C. M. Xu, Chem. Phys. Lett. 364, 57 (2002).

${ }^{17}$ U. Meier and C. Pettenkofer, Appl. Surf. Sci. 252, 1139 (2005).

${ }^{18}$ O. Kluth, B. Rech, L. Houben, S. Wieder, G. Schope, C. Beneking, H. Wagner, A. Loffl, and H. W. Schock, Thin Solid Films 351, 247 (1999).

${ }^{19}$ J. G. Ma, Y. C. Liu, C. S. Xu, Y. X. Liu, C. L. Shao, H. Y. Xu, J. Y. Zhang, Y. M. Lu, D. Z. Shen, and X. W. Fan, J. Appl. Phys. 97, 103509 (2005).

${ }^{20}$ H. Chang, H. D. Park, K. S. Sohn, and J. D. Lee, J. Korean Phys. Soc. 34, 
545 (1999).

${ }^{21}$ H. Zhang, X. Feng, and J.-Y. Kang, Chin. J. Lumin. 27, 68 (2007).

${ }^{22}$ G. Kresse and J. Furthmüller, Phys. Rev. B 54, 11169 (1996).

${ }^{23}$ X. Jiang and G. Y. Guo, Phys. Rev. B 69, 155108 (2004).

${ }^{24}$ D. Segev and S. H. Wei, Phys. Rev. B 71, 125129 (2005).

${ }^{25}$ S. Z. Karazhanov, P. Ravindran, P. Vajeeston, A. Ulyashin, H. Fjellvag, and B. G. Svensson, J. Phys.: Condens. Matter 21, 485801 (2009).

${ }^{26}$ J. P. Perdew and A. Zunger, Phys. Rev. B 23, 5048 (1981).

${ }^{27}$ D. M. Ceperley and B. J. Alder, Phys. Rev. Lett. 45, 566 (1980).

${ }^{28}$ P. E. Blöchl, Phys. Rev. B 50, 17953 (1994).

${ }^{29}$ G. Kresse and D. Joubert, Phys. Rev. B 59, 1758 (1999).

${ }^{30}$ P. Ravindran, A. Delin, R. Ahuja, B. Johansson, S. Auluck, J. Wills, and O. Eriksson, Phys. Rev. B 56, 6851 (1997).

${ }^{31}$ S. Z. Karazhanov, P. Ravindran, A. Kjekshus, H. Fjellvag, and B. G. Svensson, Phys. Rev. B 75, 155104 (2007).

${ }^{32}$ K. B. Sundaram and A. Khan, J. Vac. Sci. Technol. A 15, 428 (1997).

${ }^{33}$ X. Li, B. Zhang, X. Dong, Y. Zhang, X. Xia, W. Zhao, and G. Du, J. Lumin. 129, 86 (2009).

${ }^{34}$ W. R. L. Lambrecht, A. V. Rodina, S. Limpijumnong, B. Segall, and B. K. Meyer, Phys. Rev. B 65, 075207 (2002).
${ }^{35}$ K. Hümmer, Phys. Status Solidi B 56, 249 (1973).

${ }^{36}$ G. Henkelman, A. Arnaldsson, and H. Jonsson, Comput. Mater. Sci. 36, 354 (2006).

${ }^{37}$ C. Fonseca Guerra, J.-W. Handgraaf, E. J. Baerends, and F. M. Bickelhaupt, J. Comput. Chem. 25, 189 (2004).

${ }^{38}$ R. F. W. Bader, Atoms in Molecules: A Quantum Theory (Oxford University Press, New York, 1990).

${ }^{39}$ A. L. Allred, J. Inorg. Nucl. Chem. 17, 215 (1961).

${ }^{40}$ A. D. Becke and K. E. Edgecombe, J. Chem. Phys. 92, 5397 (1990).

${ }^{41}$ B. Silvi and A. Savin, Nature (London) 371, 683 (1994).

${ }^{42}$ P. Vajeeston, P. Ravindran, R. Vidya, A. Kjekshus, and H. Fjellvag, Europhys. Lett. 72, 569 (2005).

${ }^{43}$ H. Amekura, K. Kono, N. Kishimoto, and C. Buchal, Nucl. Instrum. Methods Phys. Res. B 242, 96 (2006).

${ }^{44}$ S. Z. Karazhanov, P. Ravindran, A. Kjekshus, H. Fjellvag, U. Grossner, and B. G. Svensson, J. Appl. Phys. 100, 043709 (2006).

${ }^{45}$ S. Adachi, Optical Constants of Crystalline and Amorphous Semiconductors. Numerical Data and Graphical Information (Kluwer Academic Publishers, Boston, Dordrecht, London, 1999). 